\title{
Comparison of Mini-implant-supported Mandibular Canine Retraction with and without Submucosal Injection of Platelet- rich Plasma: A Split-mouth Study
}

\author{
Nithin V Joy ${ }^{1}$, Hurkadle Jyothikiran ${ }^{2}$, Nagasundar Rao Raghunath ${ }^{3}$
}

\begin{abstract}
Aim and objective:To compare the differences in the rate of implant-supported individual canine retraction, with and without the administration of autologous platelet-rich plasma (PRP).

Materials and methods: Fifteen individuals who required mandibular 1st premolar extractions as part of their orthodontic therapy were selected in this split-mouth study. After the initial case strap-up followed by alignment and leveling stage using MBT 0.022 " appliance, to evaluate the effect of PRP on orthodontic tooth movement, the individual canine retraction was carried out on both the intervention and control side using the same NiTi Closed Coil Springs using a retraction force magnitude of $150 \mathrm{~g}$ measured using a Dontrix gauge. In the present study, instead of taking the conventional molar anchorage for retraction, mini-implants were utilized to prevent any mesial movement of posterior teeth (anchor loss). At the same appointment, injectable PRP was derived from the patient's own blood and was administered submucosally in the lingual mucosa and attached gingiva of canine and extraction site of the first premolar on the intervention side. Measurements for the determination of the rate of canine retraction were performed by direct technique from pre-canine retraction $\left(T^{0}\right)$ and post-canine retraction $\left(T^{1}\right)$ dental models with the help of a Vernier caliper digital instrument. The rate of canine retraction was evaluated and put through statistical analysis.

Results: The mean rate of canine retraction for the PRP group and control group was $0.87 \pm 0.12$ and $0.7 \pm 0.13 \mathrm{~mm} / \mathrm{month}$, respectively. The paired difference in the rates of the canine retraction was $0.17067 \mathrm{~mm} / \mathrm{month}$, which was found to be statistically significant $(p<0.001)$.

Conclusion: The individual canine retraction was observed to be 1.24 times efficient in the PRP group compared with the control group. The effect of PRP administration on the rate of tooth movement at different intervals of the canine retraction process needs to be evaluated in future studies.

Clinical significance: Minimally invasive techniques to speed up orthodontic treatment are the need of the hour as more individuals wish for a shorter duration of orthodontic therapy as well as not ignoring the positive effects of the same with respect to periodontal health, dental caries, and patient compliance.

Keywords: Accelerated orthodontics, Canine retraction, Mini-implant-supported retraction, Orthodontic tooth movement, Platelet-rich plasma, Split-mouth study.

World Journal of Dentistry (2021): 10.5005/jp-journals-10015-1878
\end{abstract}

\section{INTRODUCTION}

We live in an era of escalated self-consciousness, self-awareness, and self-presentation. We are not oblivious to the selfie phenomenon influencing millennials of the time. All of this translates to the heightened sense of self-esteem one seeks in society. Smile esthetics and facial appearance is an important factor in today's world and demand for orthodontic treatment has been on the rise among adolescents, more so in adults of the present time. With technological advancement came the habit of getting a hold of everything at our fingertips, which to some extent has made all of us impatient or in other words a desire to get a hold on things at the earliest. The field of medicine and dentistry has been no exception to the above mandate. Over the past few decades, countless research has been undertaken on hastening the rate of tooth movement in the field of orthodontics as demand for rapid or shorter treatment timings has been on the rise, especially among adults who seek orthodontic care. Moreover, prolonged treatment time has its own counterproductive effects such as gingival recession, dental caries, root resorption, temporomandibular joint problems, etc. There have been a plethora of techniques for accelerating orthodontic tooth movement (OTM) ranging from surgical to non-surgical methods, of which the surgical techniques have proven to be the
${ }^{1-3}$ Department of Orthodontics and Dentofacial Orthopaedics, JSS Dental College and Hospital, Mysuru, Karnataka, India

Corresponding Author: Hurkadle Jyothikiran, Department of Orthodontics and Dentofacial Orthopaedics, JSS Dental College and Hospital, Mysuru, Karnataka, India, Phone: +91 9448163485, e-mail: dr. hjyothikiran@jssuni.edu.in

How to cite this article: Joy NV, Jyothikiran $H$, Raghunath NR. Comparison of Mini-implant-supported Mandibular Canine Retraction with and without Submucosal Injection of Platelet-rich Plasma: A Splitmouth Study. World J Dent 2021;12(6):446-452.

Source of support: Nil

Conflict of interest: None

most promising. These techniques are based on the principle that when a bone is surgically wounded, an inflammatory cascade is initiated leading to osteoclastogenesis that ultimately accelerates the rate at which tooth moves within the bone (RAP-Regional Acceleratory Phenomenon). But these results do come with a price. In contrast to the noninvasive approaches, they lead to surgical injury to the bone that activates an elevated osteoclastic activity, resorption of the alveolar bone, reduction in alveolar 
bone density, and squandering of supporting bone of the teeth to be moved. Their disadvantages are that any surgical procedure is not appealing to both the patients and orthodontists and the reduction in alveolar bone volume which ultimately decreases the periodontal support of the target teeth. Other methods to mimic the effects of surgical insults involve the use of local administration of cytokines or hormones, but their clinical feasibility and safety on a systemic level raise many questions. Injection of autologous platelet-rich plasma (PRP) could be a promising substitute for bone surgery. ${ }^{1}$ Recently, a novel minimally invasive approach consisting of local administration of PRP at the site of OTM has been developed and tested to reduce the time taken for orthodontic treatment. It has been hypothesized that PRP containing a high concentration of growth factors such as platelet-derived growth factor, transforming growth factor, endothelium growth factor, and the others effectively stimulates the normal healing process and bring about rapid tooth movement mimicking other invasive procedures in bringing about RAP. Thus, this study aims to compare the differences in the rate of individual canine retraction, with and without the administration of autologous PRP.

\section{Materials and Methods}

The study sample involved individuals who presented to the Orthodontic clinic of JSSDCH as outpatients. Individuals satisfying the inclusion criteria were requested to sign an informed consent form provided they were interested in participation. Ethical clearance was obtained from the institutional ethical committee (JSSDCH IEC Research Protocol No: 20/2018).

\section{Selection Criteria}

Patients with any malocclusion that require an orthodontic treatment plan of extraction of lower first premolars and complete mandibular canine retraction within the age range of 13-25 years were selected. It was also made sure that all teeth mesial to the second molar fully erupted and periodontally healthy (absence of gingival bleeding, probing depths $<3 \mathrm{~mm}$, and no radiographic evidence of periodontal bone loss).

Patients having any medical and dental contraindications for orthodontic treatment, periodontally compromised patients, individuals with the oral manifestation of a disease or a chronic debilitating disease, or suffering from any kind of blood dyscrasias were excluded from the study.

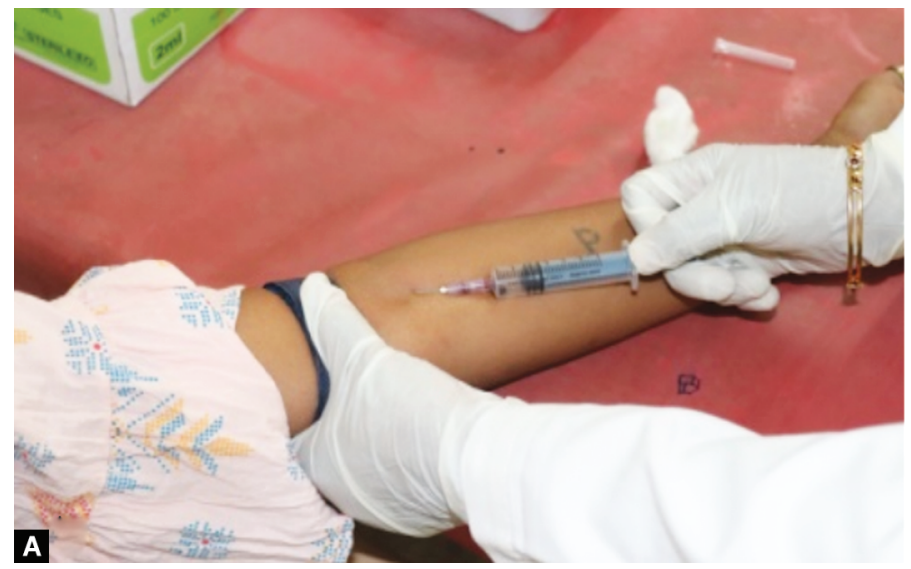

Figs $1 \mathrm{~A}$ and $\mathrm{B}$ : (A) Collection of blood followed by (B) centrifugation

\section{Study Design}

The estimated sample size was 15 sites per group. Therefore, 15 patients were recruited for the study with a split-mouth design wherein the right and left sides of the mandibular arch were randomly assigned to each of the PRP and control groups.

\section{Methods}

Before the start of treatment, patients have advised extraction of mandibular first premolars as per their treatment plan. Initial case strap-up were done using MBT 0.022" appliance followed by alignment and leveling phase before individual mandibular canine retraction could be started. Impressions were made before $\left(T^{0}\right)$ and after $\left(T^{1}\right)$ canine retraction and dental stone, models were prepared for retraction measurement.

\section{Preparation of Autologous PRP}

The autologous PRP was prepared under aseptic conditions, in the Department of Oral Pathology and Microbiology. A volume of $30 \mathrm{~mL}$ of whole blood was drawn from the medial cubital vein of a patient and $29 \mathrm{~mL}$ of blood was transferred into the vacutainers containing $3.2 \%$ sodium citrate solution as an anticoagulant. Heparin was not used as an anticoagulant due to its known systemic effects. One milliliter of the blood was used for checking the platelet counts (Fig. 1). The remaining $29 \mathrm{~mL}$ of whole blood was first centrifuged under $1,000 \mathrm{rpm}$ for 12 minutes at room temperature. The blood was then separated into its three basic components as the RBCs at the bottom, the buffy coat (platelets) in the middle, and platelet-poor plasma (PPP) at the top (Fig. 2A). The RBCs were discarded, and the remaining buffy coat and PPP were collected and centrifuged again under 3,000 rpm for 8 minutes. After the second centrifugation, the PPP was removed until $4 \mathrm{~mL}$ remained and then the remaining PPP was mixed with the buffy coat to become PRP ${ }^{1}$ (Figs 2B and C).

\section{Procedure of PRP Injection}

Before the injection of PRP, $1 \mathrm{~mL}$ of local anesthesia (2\% lignocaine) was injected at the preferred sites for pain control. One milliliter of PRP was injected in the attached buccal gingiva and lingual mucosa of canine and first premolar extraction site on the experimental side (Fig. 3). At the same appointment, a pre-retraction mandibular arch impression $\left(T^{0}\right)$ was taken.

At the same appointment after PRP administration, a miniimplant (1.3 $\times 8 \mathrm{~mm}$, Dentos AbsoAnchor, Korea) was inserted into

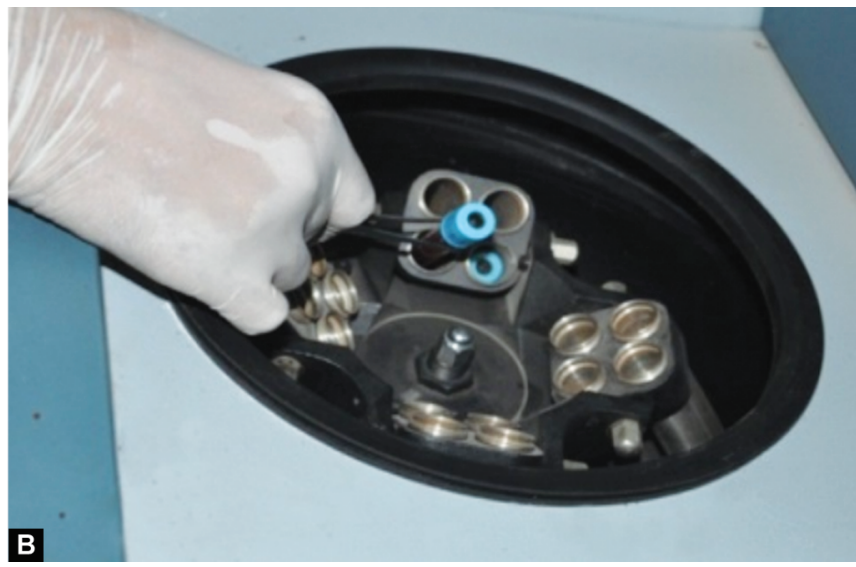



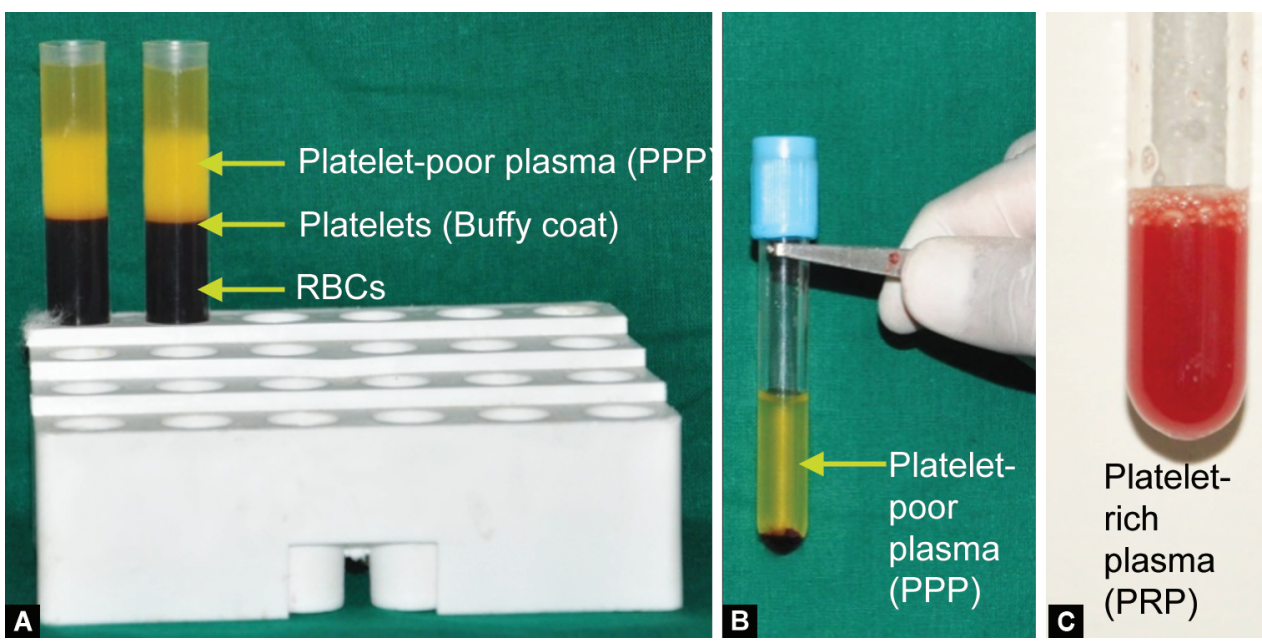

Figs 2A to C: (A) Blood after "first spin"; (B) PPP; (C) PRP after "second spin"

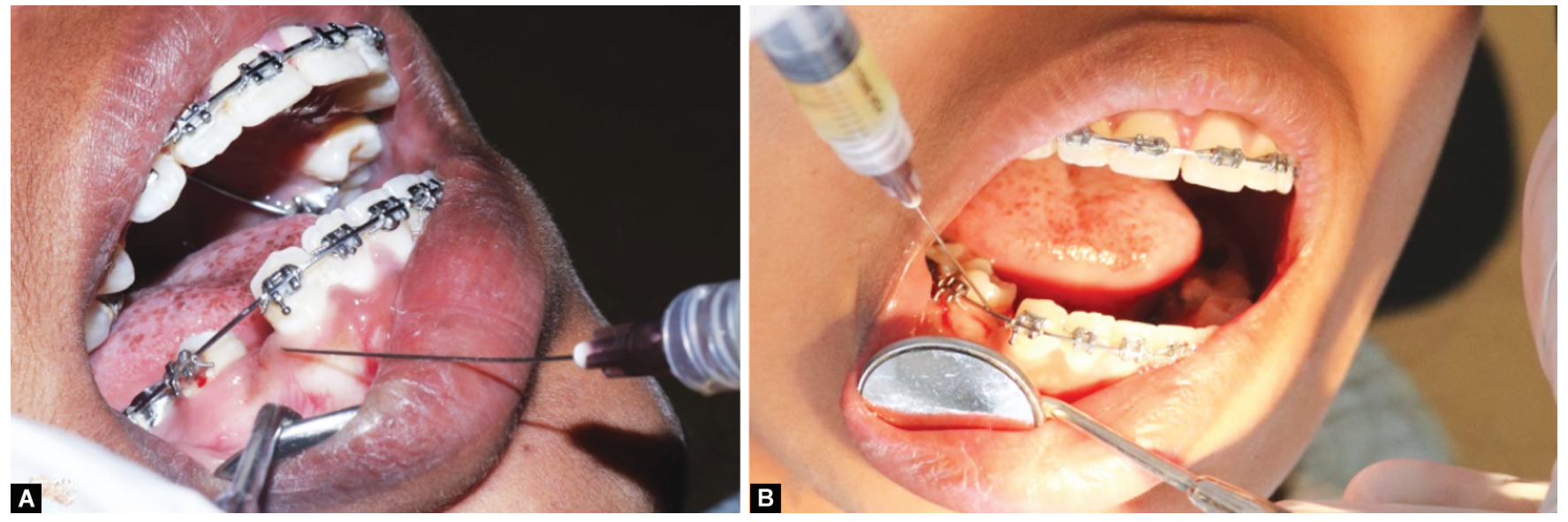

Figs $3 \mathrm{~A}$ and B: Injection of PRP at: (A) Labial; (B) Lingual mucosa of the extraction site
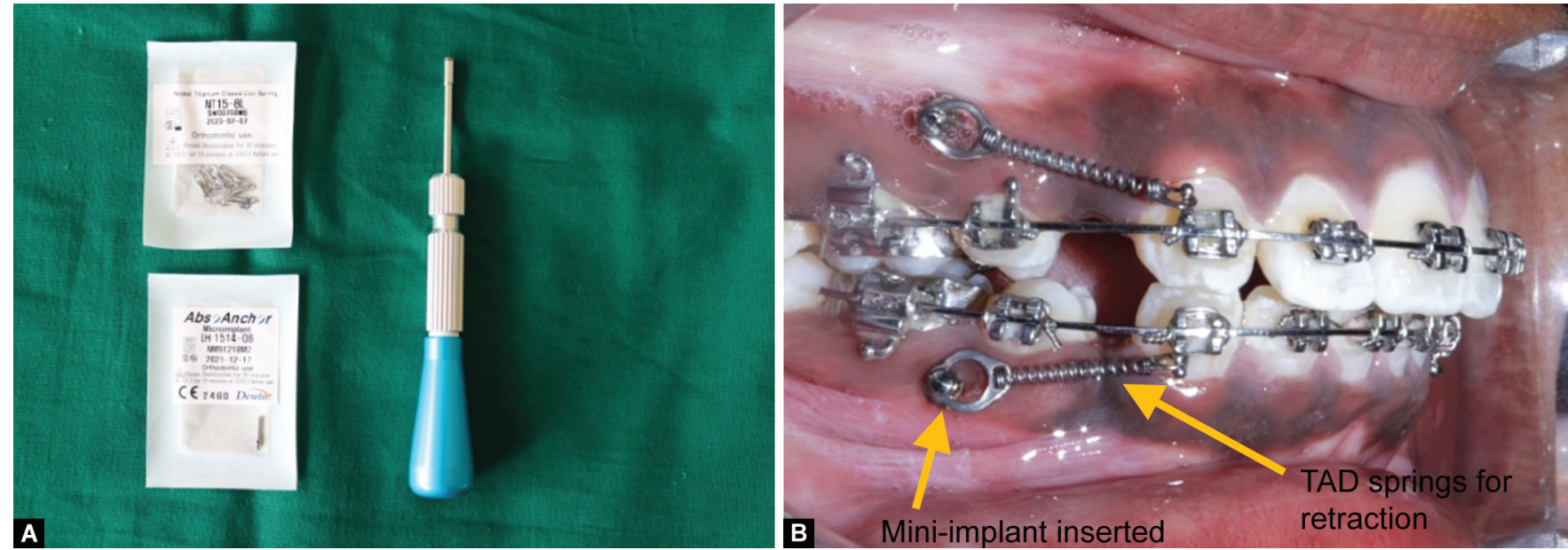

Figs 4A and B: (A) Mini-implant armamentarium; (B) NiTi closed coil springs used

buccal inter-radicular bone in-between the second premolar and first molar on either side of the mandibular arch (Fig. 4).

At the same appointment, nickel-titanium closed coil springs (TAD Springs, Dentos, Korea) extending from the mini-implant to the canine power arm in mandibular arch were placed on both the sides with equal retraction forces $(150 \mathrm{~g})$, measured using a Dontrix gauge.

Acetaminophen $(650 \mathrm{mg})$ was advised as an analgesic for postinjection pain control if needed. Study participants were recalled once monthly until canine distal movement was completed. In most 

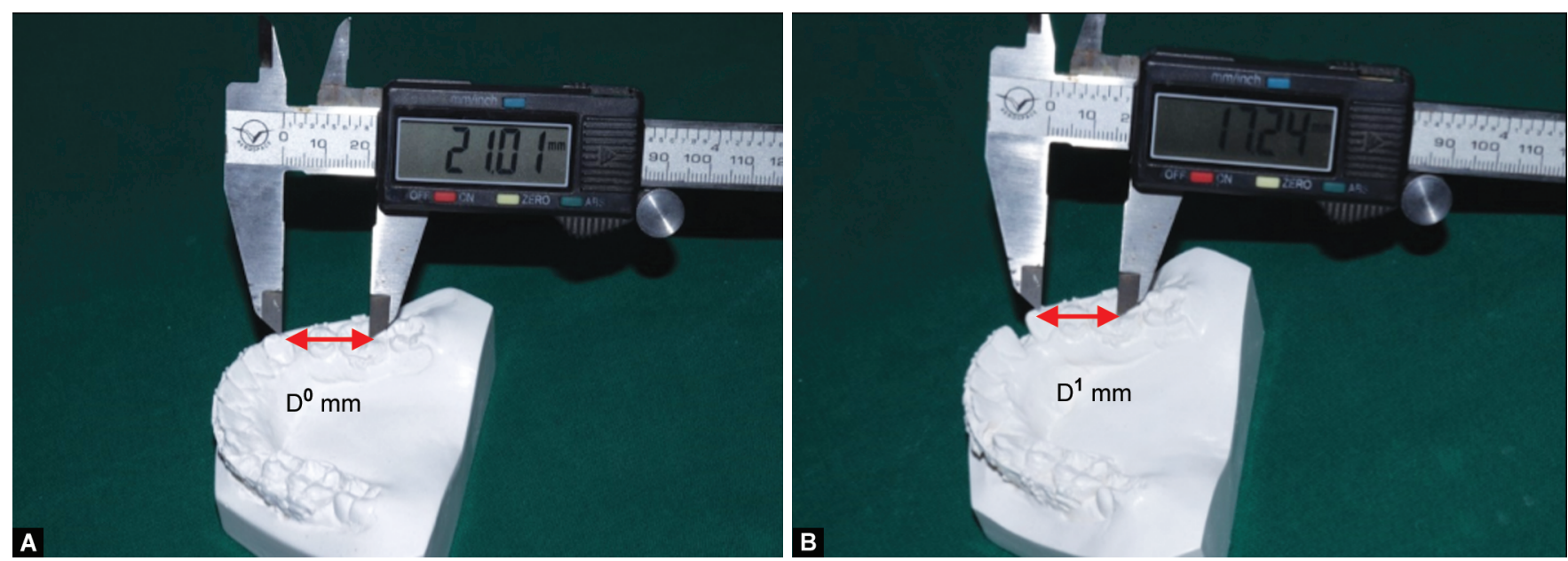

Figs 5A and B: Measurements done on: (A) Pre- and (B) Post-retraction dental stone models

Table 1:Time taken for the retraction of PRP and control groups

\begin{tabular}{llllll}
\hline Groups & $N$ & Minimum (months) & Maximum (months) & Mean (months) & SD \\
\hline PRP & 15 & 4.5 & 7.5 & 5.96 & 0.94 \\
Control & 15 & 5.5 & 9.5 & 7.42 & 1.12 \\
\hline
\end{tabular}

of the patients, two post-retraction casts $\left(T^{1}\right)$ had to be developed because of the differences in the rate of canine retraction in the PRP side and control side.

\section{Evaluation of the Rate of Canine Retraction}

All the estimations were carried out by direct method from dental casts obtained before $\left(T^{0}\right)$ and at the completion $\left(T^{1}\right)$ of retraction using a digital Vernier caliper measuring device.

Step 1: The distance $\left(D^{0} \mathrm{~mm}\right)$ between the cusp tip of the permanent mandibular canine ( $C^{1}$ point) and the central fossa of the permanent mandibular first molar ( $F^{1}$ point) was evaluated using digital Vernier caliper on pre-retraction dental stone model $\left(T^{0}\right)$.

Step 2: In the post-retraction dental stone model $\left(T^{1}\right)$, the interspace between the $C^{1}$ point and the $F^{1}$ point was evaluated again utilizing the same digital Vernier caliper and this distance was designated as $D^{1} \mathrm{~mm}$.

Step 3: The difference between the distances in steps 1 and $2\left(D^{0}-D^{1} \mathrm{~mm}\right)$ gave the distance traversed by the permanent mandibular canine during the entire retraction process.

Step 4: The rate of individual canine retraction was obtained by dividing the distance covered by the permanent canine $\left(D^{0}-D^{1}\right.$ $\mathrm{mm}$ ) with the number of intervals (in months) consumed for the same $\left(T^{0}-T^{1}\right)$.

All measurements were recorded by a single investigator, repeated thrice and the mean values for all observations were obtained (Fig. 5).

The total duration of the study was 1.5 years (January 2019 to June 2020).

\section{Statistical Analysis}

Data obtained were analyzed using SPSS version 22.0 for Windows. The descriptive statistics that were employed in the present study were mean, standard deviation, and standard error of the mean. The paired-samples $t$-tests were employed to compare the means of two groups.

\section{Results}

The present study was undertaken to measure the differences in the rate of the mandibular canine retraction with and without submucosal administration of PRP with the help of mini-implants as posterior absolute anchorage unit.

The parent sample consisted of 15 patients, out of which 6 were males and 9 were females. The mean age was $21.7 \pm 2.52$ years. In this split-mouth study, PRP was injected in the attached gingiva and lingual mucosa of canine and extraction site of mandibular first premolar on the PRP side.

The mean time taken for the complete retraction of the canine for the PRP group and the control group was $5.96 \pm 0.94$ and 7.42 \pm 1.12 months, respectively (Table 1 and Fig. 6).

The maximum rate of canine retraction for the PRP group was $1.13 \mathrm{~mm} / \mathrm{month}$ and for the control group, it was $0.96 \mathrm{~mm} / \mathrm{month}$. The minimum rate of canine retraction was $0.65 \mathrm{~mm} / \mathrm{month}$ for the PRP group and $0.47 \mathrm{~mm} / \mathrm{month}$ for the control group. The mean rate of canine retraction for the PRP group and control group was $0.87 \pm$ 0.12 and $0.7 \pm 0.13 \mathrm{~mm} / \mathrm{month}$, respectively. The paired difference observed was $0.17067 \mathrm{~mm} / \mathrm{month}$, which was statistically significant $(p<0.001)$ (Tables 2 and 3, Fig. 6).

The individual canine retraction was found to be 1.24 times accelerated in the PRP group compared to the control group.

\section{Discussion}

Out of the many detrimental factors hampering a person to smile, a major one is a malocclusion. The WHO estimates that malocclusion is one among the three most prevalent oral health problems, the others being dental caries and periodontal diseases. ${ }^{2}$ As a result, the demand for orthodontic treatment is on the rise especially among adults and so is for shorter treatment duration. It appears there is no common consensus regarding overall orthodontic treatment duration. A recent systematic review revealed average treatment duration of 2 years (19.9 months). However, a wide 

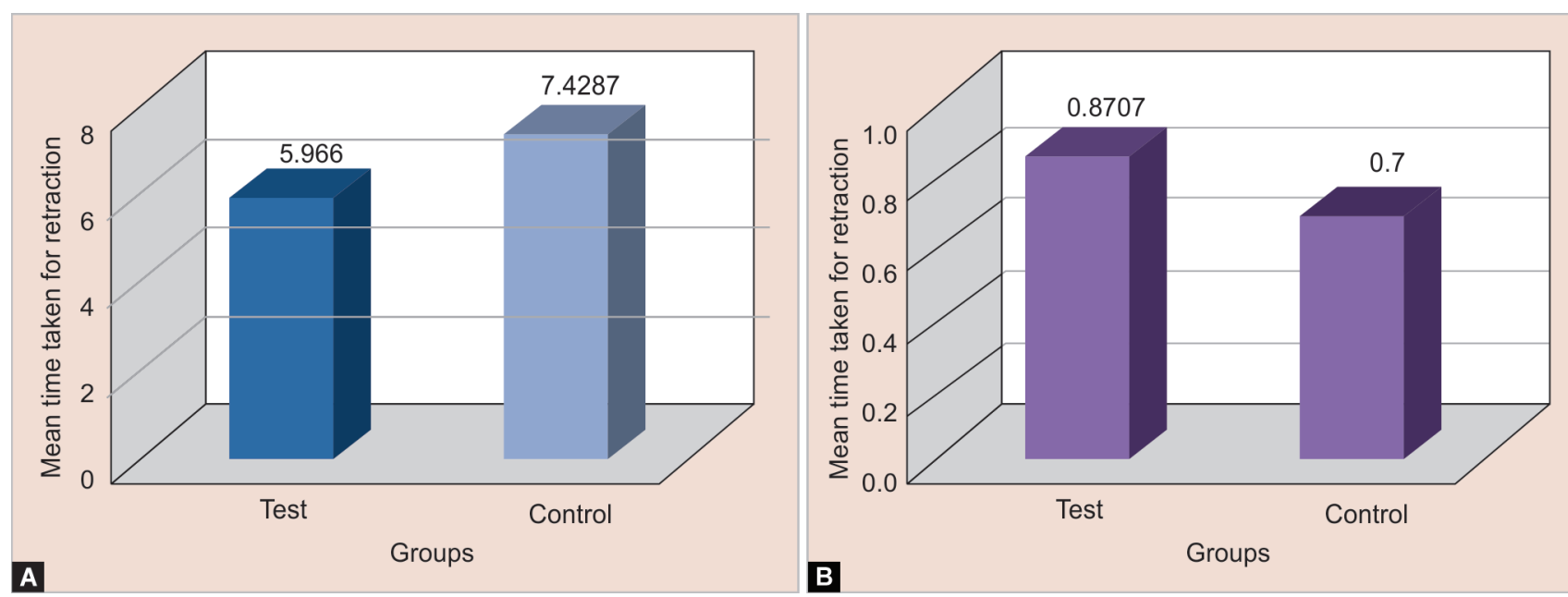

Figs $6 \mathrm{~A}$ and $\mathrm{B}$ : (A) Mean time taken for the retraction; (B) Mean rate of retraction

Table 2: Rate of retraction compared between PRP and control groups

\begin{tabular}{llllll}
\hline Groups & $N$ & $\begin{array}{l}\text { Minimum } \\
(\mathrm{mm} / \text { month) }\end{array}$ & $\begin{array}{l}\text { Maximum } \\
(\mathrm{mm} / \text { month) }\end{array}$ & $\begin{array}{l}\text { Mean } \\
(\mathrm{mm} / \text { month) }\end{array}$ & SD \\
\hline PRP & 15 & 0.65 & 1.13 & 0.87 & 0.12 \\
Control & 15 & 0.47 & 0.96 & 0.7 & 0.13 \\
\hline
\end{tabular}

Table 3: Paired samples " $t$ " test conducted between PRP and control group

\begin{tabular}{|c|c|c|c|c|}
\hline \multicolumn{2}{|c|}{ Paired differences } & \multirow[b]{2}{*}{$t$} & \multirow[b]{2}{*}{$d f$} & \multirow[b]{2}{*}{ Significance } \\
\hline Mean & Std. deviation & & & \\
\hline 0.17067 & 0.11750 & 5.625 & 14 & $p<0.001$ \\
\hline
\end{tabular}

range of treatment durations (14-33 months) were reported in the orthodontic literature. ${ }^{3}$

But the interesting fact is that when patients (adults, adolescents) and parents were asked about how long they would like treatment to last, $40.8 \%$ of adolescent patients answered less than 6 months, while $33.2 \%$ of them answered between 6 months and 12 months whereas, among adult patients, $42.9 \%$ answered between 6 months and 12 months, while $26.5 \%$ answered between 12 months and 18 months. ${ }^{4}$ This shows that not only will shorter treatment duration translate to better patient compliance and satisfaction but also reported to have a fewer incidence of iatrogenic factors like dental caries, gingival recession, and root resorption among many. ${ }^{5}$

The RAP was described first by Harold Frost as "a tissue reaction to different noxious stimuli that leads to recruitment of BMUs (basic multicellular units) that works overtime by which tissue regenerates faster than normal in a regional regeneration/remodeling process". 6 It is a heightened reaction that varies directly in duration, size, and intensity depending on the intensity of the stimulus, and is regarded a physiological "emergency" process that ultimately hastens the healing responses. The extent of RAP response is based on the character of tissue and mostly persists for nearly 4 months in human bone. This event brings about bone turnover 10-50 times faster than usual. Surgical techniques, such as corticotomies, piezocision, etc., that make use of the above phenomenon have been tried and tested and have proven to be quite successful in accelerating the rate of OTM. But these at the end of the day have their own degree of invasiveness and discomfort and would not be a patient's as well as a clinician's go-to choice at any point in time. This is where the quest for minimally invasive techniques to accelerate OTM gains its significance. In fact, a study conducted by Uribe et al. in 2014 points outpatients preferred minimally invasive techniques over traditional surgical methods as adjuncts to reduce orthodontic treatment time. ${ }^{4}$

Recently, a new technique has been proposed and tested where autologous PRP has been locally administered at the site of OTM as a means to accelerate the rate of tooth movement. It has been hypothesized that PRP can simulate the effects induced by the surgical therapy without having the disadvantage of invasiveness or aggressiveness as the case with the various surgical approaches. ${ }^{1}$

Platelet-rich plasma is essentially an increased concentration of autologous platelets suspended in a small amount of plasma after centrifugation. ${ }^{7}$ Basically, the patient's blood is collected and centrifuged at varying speeds until it separates into three layers: PPP, PRP, and red blood cells. Usually, two spins are used. The first spin ("Hard spin") separates the PPP from the red fraction and PRP. The second spin ("Soft spin") separates the red fraction from the PRP. The material with the highest specific gravity (PRP) will be deposited at the bottom of the tube. The whole process takes approximately 20 minutes and produces a platelet concentration of 3-5x that of native plasma. ${ }^{8}$

According to Liou, "single injection of PRP activity lasts for 5-6 months clinically and the fastest rate of acceleration is during the second to fourth month after the injection. According to his study, single injection of PRP in the beginning of treatment for the purpose of alignment and levelling is sufficient". ${ }^{1}$ Same dosage pattern and injection technique was followed as described by Liou in his study.

In the present study, PRP was injected in the attached gingiva and lingual mucosa of the canine and first premolar extraction site on the experimental side of the mandibular arch. To make sure that an identical amount of retraction forces are utilized for the canine 
retraction, the retraction auxiliary used in both the experimental and control side was nickel titanium closed coil springs $(9 \mathrm{~mm}$ length) with TAD heads extending from the posterior implant head (placed between mandibular 1st molar and 2nd premolar) and the canine bracket power arm. A 100-150 $\mathrm{g}$ force is traditionally used in single canine retraction, therefore for the present study a $150 \mathrm{~g}$ force was employed that was measured using a Dontrix gauge. ${ }^{9}$

In the present study, microimplants were utilized to retract the mandibular canines instead of taking anchorage from the posterior molar teeth which made sure that there was absolutely no amount of anchorage loss that could have occurred or in other words the complete space gained by extraction of 1st bicuspid was utilized absolutely for canine retraction and did not result in mesial movement of the molar.

\section{Effect of PRP during Canine Retraction}

During a comparison of the mean retraction rate of mandibular canine in the present study, it was seen that the PRP side was 1.24 times faster than the control side. When we interpret the abovementioned result from a clinical point of view, the mandibular canine on the PRP side retracted completely by around 1.46 months faster than the control side. This acceleration would have been due to the enhanced wound healing process and bone turnover at the PRP site due to a local rise in the concentration of available growth factors released from the platelets.

There have been not many clinical studies evaluating the rate of mandibular canine retraction especially using novel methods like PRP in the orthodontic literature. Much of the orthodontic literature have compared the rate of retraction in the maxillary arch. Despite the inconsistencies, there is a general agreement that the rate of retraction in the mandibular arch is slower than the maxillary arch owing to the differences in bone density and remodeling rate. ${ }^{10,11}$

Much of the studies in orthodontic literature for canine retraction used conventional molar anchorage that has resulted in anchorage loss of some degree. A study by da C Monini et al. ${ }^{12}$ reported a mean anchorage loss of $1.27 \pm 1.23$ and $1.29 \pm 0.86 \mathrm{~mm}$ in the maxillary and mandibular arch, respectively. Another study by Thiruvenkatachari and associates reported mean anchorage loss of $1.60 \mathrm{~mm}$ in the maxilla and $1.70 \mathrm{~mm}$ in the mandible on the molar anchorage side and no anchorage loss on the implant side suggesting that mini-implants are an efficient mode of absolute anchorage. ${ }^{13}$ The present study also utilized mini-implants as posterior anchorage units so that the whole of the premolar extraction space could be utilized for mandibular canine retraction and the process was not confounded by the mesial movement of molars.
Davis et al. conducted a study to compare the rate of canine retraction, the anchorage loss, and the change in the inclination of the first molars between the molar and mini-implant anchorage. The mean rate of mandibular canine retraction observed where 0.81 and $0.76 \mathrm{~mm} / \mathrm{month}$ on the implant and molar sides, respectively. ${ }^{14}$ The study by da C. Monini et al. investigated the canine retraction rate and anchorage loss using self-ligating (SL) brackets and conventional (CV) brackets. ${ }^{12}$ They found the canine retraction rate in the mandibular arch to be 0.54 and $0.60 \mathrm{~mm}$ in the SL and CV groups, respectively. The results of the present study in relation to the rate of mandibular cuspid retraction are congruous with the above studies with the mean rate of retraction in the control group is $0.7 \mathrm{~mm} / \mathrm{month}$ whereas in the intervention group (PRP group) it was seen significantly improved at $0.87 \mathrm{~mm} /$ month.

A study conducted by El-Timamy et al. to investigate the effect of PRP on OTM in the maxillary arch demonstrated a 1.15 times increase in the rate of retraction when compared with the control group..$^{15}$ Another study conducted by Liou et al. revealed that "injection of PRP accelerated the mandibular or maxillary anterior teeth alignment 1.7 folds in average". ${ }^{1}$ The results of the present study are concordant with the above studies wherein an acceleration of mandibular canine retraction in the PRP side by 1.24 times faster than the control group was observed.

A comparative evaluation of the present study with other proposed and experimented modes of techniques to accelerate OTM has been made in Table 4, which gives us an insight into how PRP could become a sensible alternative in accelerating tooth movement in day-to-day clinical practice.

\section{Limitation of the Study}

The sample size of the present study was 15 sites/group. More studies with larger participant groups are required to confirm the results of this study. Also, the effect of PRP administration on the rate of tooth movement at different intervals of the canine retraction process was not evaluated which warrants further research.

\section{CONCLUSION}

Within the constraints of the current study, it can be deduced that: Submucosal injection of autologous PRP is an innovative, comfortable, safe, and minimally invasive method to accelerate tooth movement during orthodontic treatment. A 1.24 folds acceleration of tooth movement was found between the PRP and control group during canine retraction. More studies on the effect of PRP administration on the rate of tooth movement at different intervals of the canine retraction process warrant further investigations.

Table 4: Comparison with other accelerated techniques of tooth movement

\begin{tabular}{|c|c|c|c|c|}
\hline $\begin{array}{l}\text { Technique for acceleration } \\
\text { of canine retraction }\end{array}$ & Author & Year & Result of the study & Comparison with present study \\
\hline $\begin{array}{l}\text { Dentoalveolar distraction } \\
\text { (DAD) }\end{array}$ & Kurt et al. ${ }^{16}$ & 2010 & $\begin{array}{l}\text { Acceleration of canine retraction } \\
\text { by } 2 \text { folds }\end{array}$ & $\begin{array}{l}\text { Rapid canine retraction compared to PRP ( } 1.24 \\
\text { folds) }\end{array}$ \\
\hline $\begin{array}{l}\text { Micro-osteoperforations } \\
\text { (MOP) }\end{array}$ & $\begin{array}{l}\text { Alikhani } \\
\text { et al. }{ }^{17}\end{array}$ & 2013 & $\begin{array}{l}\text { Acceleration of canine retraction } \\
\text { by } 2.3 \text { folds }\end{array}$ & $\begin{array}{l}\text { Rapid canine retraction compared to PRP ( } 1.24 \\
\text { folds) }\end{array}$ \\
\hline $\begin{array}{l}\text { Low-level laser therapy } \\
\text { (LLLT) }\end{array}$ & $\begin{array}{l}\text { Heravi } \\
\text { et al. }{ }^{18}\end{array}$ & 2014 & $\begin{array}{l}\text { No notable enhancement in the } \\
\text { rate of cuspid retraction }\end{array}$ & PRP revealed rapid canine retraction by 1.24 folds \\
\hline $\begin{array}{l}\text { Corticotomy vs prosta- } \\
\text { glandin E1 injection }\end{array}$ & $\begin{array}{l}\text { Rajasekaran } \\
\text { et al. }{ }^{19}\end{array}$ & 2015 & $\begin{array}{l}\text { Acceleration of canine retraction } \\
\text { by } 1.6 \text { folds for corticotomy and } 1.2 \\
\text { folds for PGE1 injection }\end{array}$ & $\begin{array}{l}\text { Acceleration in canine retraction by PRP ( } 1.24 \text { folds) } \\
\text { was less than corticotomy and marginally better } \\
\text { when compared to PGE1 injection }\end{array}$ \\
\hline
\end{tabular}




\section{References}

1. Liou EJ. The development of submucosal injection of platelet rich plasma for accelerating orthodontic tooth movement and preserving pressure side alveolar bone. APOS Trends Orthod 2016;6(1):5-11. DOI: 10.4103/2321-1407.173725.

2. Guo L, Feng Y, Guo HG, et al. Consequences of orthodontic treatment in malocclusion patients: clinical and microbial effects in adults and children. BMC Oral Health 2016;16(1):1-7. DOI: 10.1186/s12903-0160308-7.

3. Tsichlaki A, Chin SY, Pandis N, et al. How long does treatment with fixed orthodontic appliances last? a systematic review. Am J Orthod Dentofac Orthop 2016;149(3):308-318. DOI: 10.1016/j. ajodo.2015.09.020.

4. Uribe F, Padala S, Allareddy V, et al. Patients', parents', and orthodontists' perceptions of the need for and costs of additional procedures to reduce treatment time. Am J Orthod Dentofac Orthop 2014;145(4):S65-S73. DOI: 10.1016/j.ajodo.2013.12.015.

5. Wilcko MT, Wilcko WM, Bissada NF. An evidence-based analysis of periodontally accelerated orthodontic and osteogenic techniques: a synthesis of scientific perspectives. In Seminars in orthodontics, vol. 14, No. 4. WB Saunders; 2008. pp. 305-316.

6. Frost HM. The regional acceleratory phenomenon: a review. Henry Ford Hospital Med J 1983;31(1):3-9.

7. Marx RE, Carlson ER, Eichstaedt RM, et al. Platelet-rich plasma: growth factor enhancement for bone grafts. Oral Surg Oral Med Oral Pathol Oral Radiol Endodontol 1998;85(6):638-646. DOI: 10.1016/s10792104(98)90029-4.

8. Petrungaro PS. Using platelet-rich plasma to accelerate soft tissue maturation in esthetic periodontal surgery. Compend Contin Educat Dent, (Jamesburg, NJ: 1995) 2001;22(9):729-732.

9. Ziegler P, Ingervall B. A clinical study of maxillary canine retraction with a retraction spring and with sliding mechanics. Am J Orthod Dentofac Orthoped 1989;95(2):99-106. DOI: 10.1016/08895406(89)90388-0.
10. Park HS, Lee YJ, Jeong SH, et al. Density of the alveolar and basal bones of the maxilla and the mandible. Am J Orthod Dentofac Orthop 2008;133(1):30-37. DOI: 10.1016/j.ajodo.2006.01.044.

11. Iwasaki LR, Haack JE, Nickel JC, et al. Human tooth movement in response to continuous stress of low magnitude. Am J Orthod Dentofac Orthop 2000;117(2):175-183. DOI: 10.1016/s08895406(00)70229-0.

12. da C, Monini A, Gandini LG, et al. Tooth movement rate and anchorage lost during canine retraction: a maxillary and mandibular comparison. The Angle Orthodon 2019;89(4):559-565. DOI: 10.2319/061318-443.1.

13. Thiruvenkatachari B, Pavithranand A, Rajasigamani K, et al. Comparison and measurement of the amount of anchorage loss of the molars with and without the use of implant anchorage during canine retraction. Am J Orthod Dentofac Orthop 2006;129(4):551-554. DOI: 10.1016/j.ajodo.2005.12.014.

14. Davis D, Krishnaraj R, Duraisamy S, et al. Comparison of rate of canine retraction and Anchorage potential between mini-implant and conventional molar anchorage: an in vivo study. Contemp Clin Dentis 2018;9(3):337. DOI: 10.4103/ccd.ccd_837_17.

15. El-Timamy A, El Sharaby F, Eid F, et al. Effect of platelet-rich plasma on the rate of orthodontic tooth movement: a split-mouth randomized trial. Angle Orthod 2020;90(3):354-361. DOI: 10.2319/072119-483.1.

16. Kurt $G$, Işeri $H$, Kişnişci R. Rapid tooth movement and orthodontic treatment using dentoalveolar distraction (DAD) long-term ( 5 years) follow-up of a class II case. Angle Orthodont 2010;80(3):597-606. DOI: 10.2319/041209-209.1.

17. Alikhani M, Raptis M, Zoldan B, et al. Effect of micro-osteoperforations on the rate of tooth movement. Am J Orthod Dentofac Orthop 2013;144(5):639-648. DOI: 10.1016/j.ajodo.2013.06.017.

18. Heravi F, Moradi A, Ahrari F. The effect of low level laser therapy on the rate of tooth movement and pain perception during canine retraction. Oral Health Dent Manag 2014;13(2):183-188.

19. Rajasekaran UB, Nayak UK. Effect of prostaglandin E1 versus corticotomy on orthodontic tooth movement: an in vivo study. Indian J Dent Res 2014;25(6):717. DOI: 10.4103/0970-9290.152170. 